\title{
Postal code diagnosis and treatment of sleep apnea
}

\author{
John A Fleetham MD
}

I $\mathrm{n}$ the current issue of the Canadian Respiratory Journal, Rotenberg et al (1) (pages 170-174) report data from a crosssectional survey sent to otolaryngologists, respirologists and family physicians in Ontario, to characterize wait times for obstructive sleep apnea (OSA) care. The major finding was that patients with suspected OSA in Ontario waited a mean of 11.6 months to initiate continuous positive airway pressure (CPAP) treatment and 16.2 months to initiate surgical therapy. This is much longer than the wait time in the Canadian Thoracic Society (CTS) guidelines, which recommend a maximum wait time of two to four weeks for urgent patients with comorbid disease or daytime sleepiness and a critical safety occupation, and six months for all patients with suspected OSA $(2,3)$. Excessive diagnostic wait times frequently lead to inappropriate or incorrect therapy. Wait times for the diagnosis of sleep apnea in Canada have not improved much since Flemons et al (4) reviewed wait times for the diagnosis of OSA in five countries, including Canada, 16 years previously. To paraphrase what Pack (5) wrote in an associated editorial: "It seems inconceivable that we should tell a patient the following: You are highly likely to have severe sleep apnea, a disorder associated with an increased risk of car crashes, high blood pressure, and probably heart attack and stroke. We have an effective treatment for this disorder. We will arrange a study for you in 11.6 months' time to assess this". The even longer wait time for surgical treatment of OSA reported by Rotenberg et al also merits comment. The role of corrective upper airway surgery in the treatment of OSA is controversial. The current CTS guidelines conclude that laser-assisted uvulopalatoplasty is not recommended for the treatment of OSA, but that uvulopalatopharyngoplasty may be considered in selected patients with OSA who have failed CPAP and/or oral appliance therapy.

The delay in the diagnosis and treatment of OSA in Ontario needs to be put in the context of the rest of Canada, where the diagnosis and treatment of sleep apnea is provided in a very different manner. Ontario has the highest number of sleep laboratories in Canada and most other parts of the world apart from the United States (4). Moreover, Ontario is one of the few provinces, along with Manitoba and Saskatchewan, in which the provincial medical plan funds CPAP treatment. The majority of centres in Canada outside of Ontario use ambulatory sleep monitoring - in addition to polysomnography - to diagnose OSA. After OSA has been diagnosed, there is no additional delay in the provision of CPAP therapy because this is funded by the patient and does not require approval by a funding agency. The majority of respondents to the survey in the article by Rotenberg et al (1) identified 'not enough sleep laboratories' as the reason for long wait times. Many would argue that more sleep laboratories are not what is required - what is necessary is a more appropriate diagnostic strategy that uses clinical prediction equations and ambulatory sleep monitoring (6) in conjunction with polysomnography for patients with comorbid disease or who fail to improve with CPAP treatment. Furthermore, if resources for the management of OSA are to be rationed, a higher priority should be given to treatment than to diagnosis. Patients with OSA use health care services at approximately twice the rate of control subjects for up to 10 years before the diagnosis of OSA (7). CPAP treatment has an incremental cost-effectiveness ratio of $\$ 2,618$ per quality-adjusted life year over no treatment (8). A ratio of less than $\$ 10,000$ per qualityadjusted life year is generally considered to be extremely cost effective.

While CPAP treatment for OSA is funded in many other countries including the United Kingdom (9) and the United States (10), it is not funded in the majority of Canadian provinces. In 2008, The Lung Association and the CTS jointly recommended funding of CPAP treatment under all provincial and federal health insurance plans for adults and children appropriately diagnosed with OSA; however, little progress has been made over the past two years. It is now time to end the postal code differences that currently exist in Canada with regard to access to the diagnosis and treatment of OSA.

\section{REFERENCES}

1. Rotenberg BW, George CF, Sullivan KM, Wong E. Wait times for sleep apnea care in Ontario: A multidisciplinary assessment. Can Respir J 2010;17:170-4.

2. Fleetham J, Ayas N, Bradley D, et al; CTS Sleep Disordered Breathing Committee. Canadian Thoracic Society Guidelines: Diagnosis and treatment of sleep disordered breathing in adults. Can Respir J 2006;13:387-92.

3. Fleetham J, Ayas N, Bradley D, et al. Directives de la Société canadienne de thoracologie: Diagnostic et traitement des troubles respiratoires du sommeil de l'adulte. Can Respir J 2007;14:31-6.

4. Flemons WW, Douglas NJ, Kuna ST, Rodenstein DO, Wheatley J. Access to diagnosis and treatment of patients with suspected sleep apnea. Am J Respir Crit Care Med 2004;169:668-72.

5. Pack AI. Sleep-disordered breathing: Access is the issue. Am J Respir Crit Care Med 2004;169:666-7.

6. Mulgrew AT, Fox N, Ayas NT, Ryan CF. Diagnosis and initial management of obstructive sleep apnea without polysomnography: A randomized validation study. Ann Intern Med 2007;146:157-66.

7. Albarrak M, Banno K, Sabbagh AA, et al. Utilization of healthcare resources in obstructive sleep apnea syndrome: A 5-year follow-up study in men using CPAP. Sleep 2005;28:1306-11.

8. Ayas NT, FitzGerald JM, Fleetham JA, et al. A cost-effectiveness analysis of continuous positive airway pressure (CPAP) therapy versus no CPAP therapy for obstructive sleep apnea hypopnea. Arch Int Med 2006;166:977-84.

9. National Institute for Health and Clinical Excellence, London, UK. $<$ http://www.nice.org.uk/guidance/index. jsp?action $=$ byID\&o $=11944>($ Accessed on June 8, 2010).

10. Centers for Medicare \& Medicaid Services, Decision Memo for Continuous Positive Airway Pressure (CPAP) Therapy for Obstructive Sleep Apnea (OSA) (CAG-00093R2). <https://www. cms.hhs.gov/mcd/viewdecisionmemo.asp?from2 =viewdecisionmemo. asp\&id=204\&> (Accessed on June 8, 2010).

\footnotetext{
The Lung Centre, Vancouver, British Columbia

Correspondence: Dr John A Fleetham, The Lung Centre, 7th Floor, 2775 Laurel Street, Vancouver, British Columbia V5Z 1 M9.

Telephone 604-875-5653, fax 604-875-5587,e-mail john.fleetham@vch.ca
} 


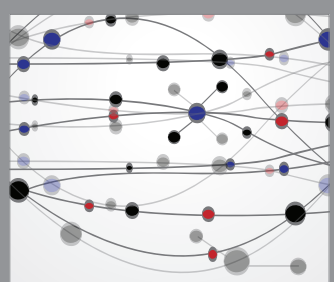

The Scientific World Journal
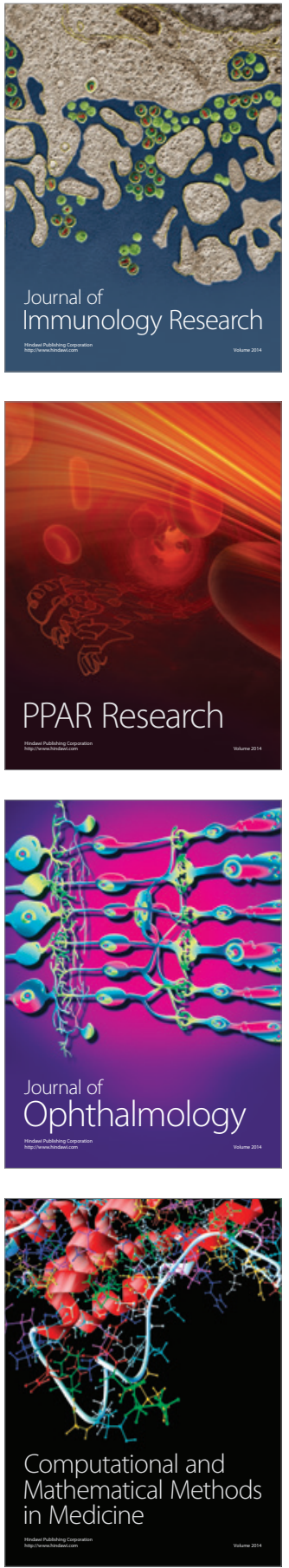

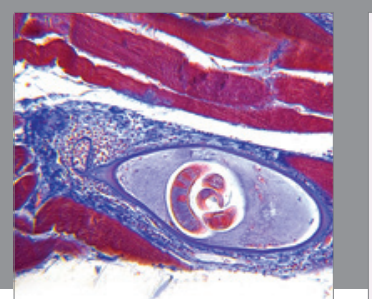

Gastroenterology Research and Practice

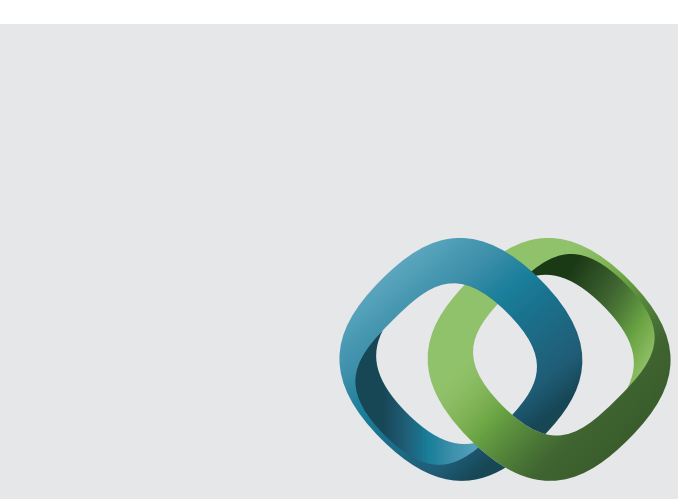

\section{Hindawi}

Submit your manuscripts at

http://www.hindawi.com
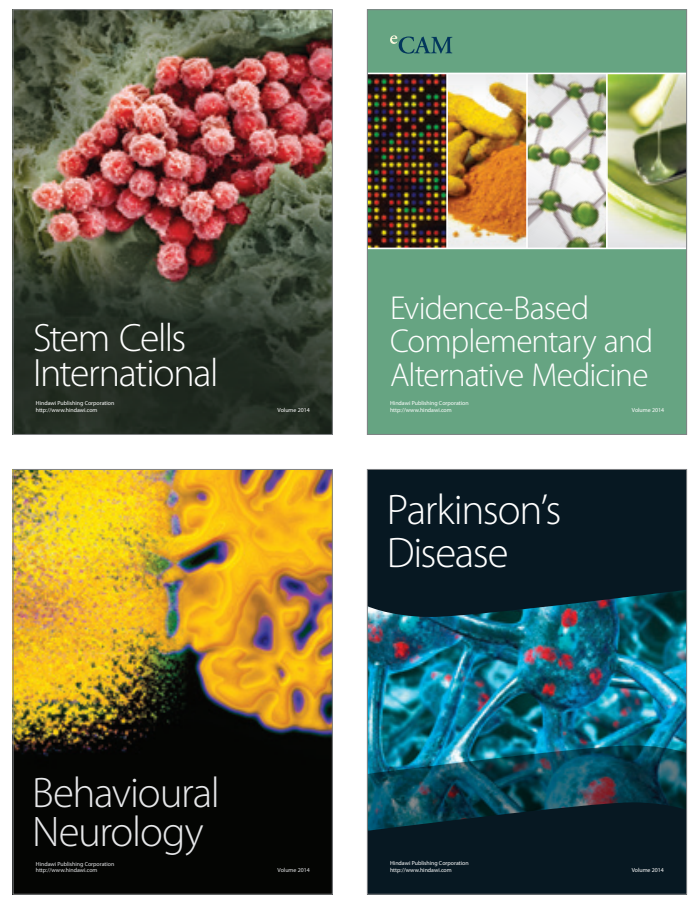
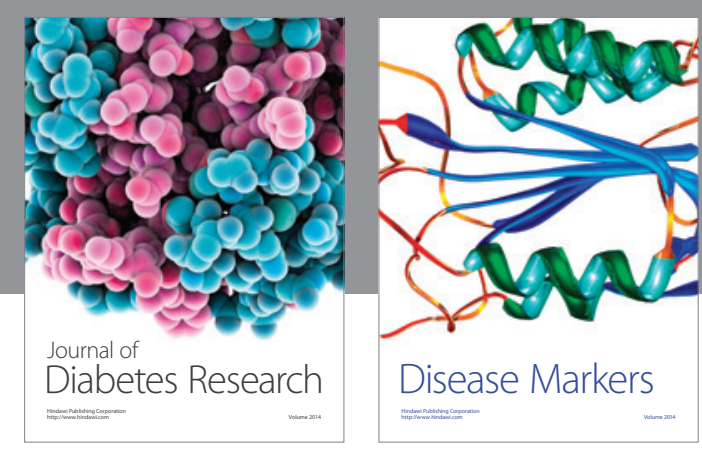

Disease Markers
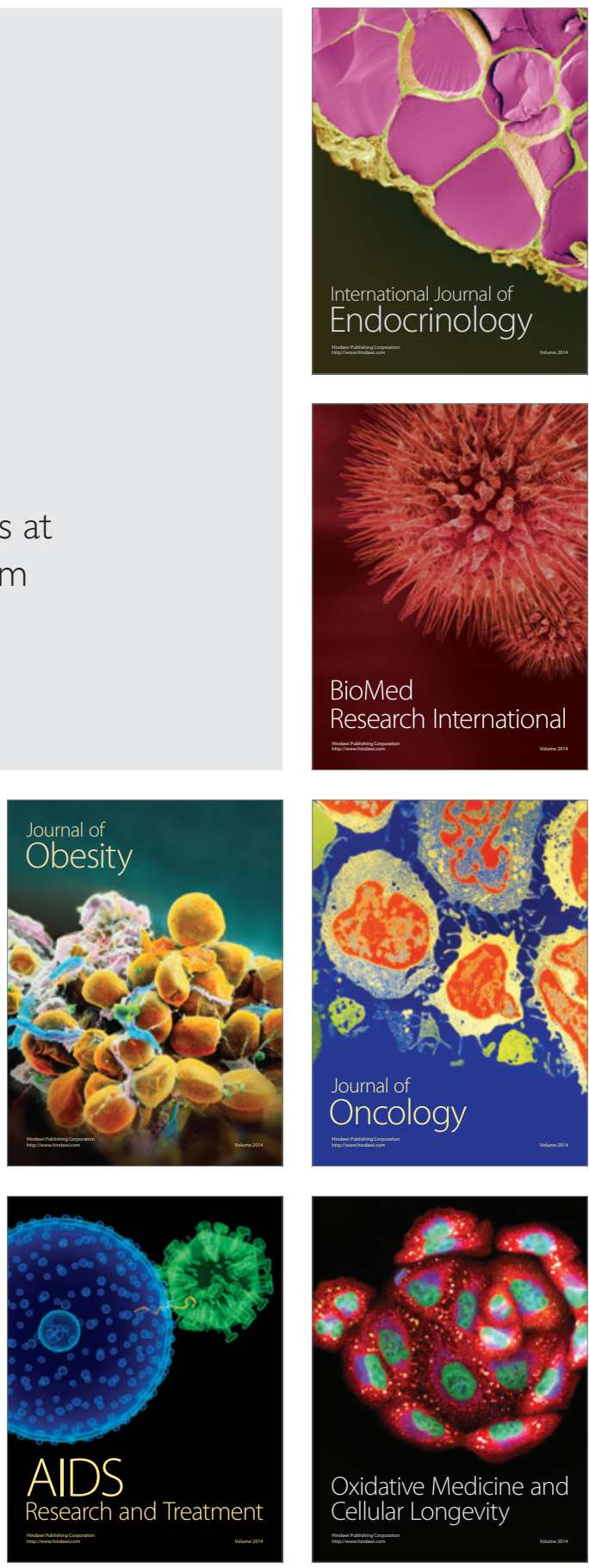